\title{
A linguagem e a vida: reflexões acerca de língua e literatura
}

Daiane Neumann"

\section{Resumo}

$\mathrm{O}$ presente texto objetiva apresentar uma leitura do capítulo "Vista d'olhos sobre o desenvolvimento da linguística", de Émile Benveniste, publicado em Problemas de Linguística Geral I. Essa reflexão busca atentar para a particularidade da leitura feita pelo linguista acerca do pensamento saussuriano, bem como para o que propõe Benveniste, enquanto sucessor dessa linguística já existente. $\mathrm{Na}$ segunda parte do texto, são apresentadas reflexões que envolvem língua e literatura e que se propõem como uma continuidade do pensamento benvenistiano, sustentadas, em grande parte, pela poética do discurso de Henri Meschonnic.

Palavras-chave: A linguagem e a vida. Língua e literatura. Émile Benveniste. Henri Meschonnic.
O texto que ora apresento propõe-se como uma leitura do artigo pelo qual me responsabilizei para apresentar no $2^{\circ}$ Colóquio Leituras de Émile Benveniste, "Vista d'olhos sobre o desenvolvimento da linguística", publicado em originalmente em 1963 e, mais tarde, em 1966, na compilação Problemas de Linguística Geral I.

Inicialmente, gostaria de pontuar que esta leitura não se trata de uma tentativa de resgatar um Benveniste "verdadeiro", mas apontar uma "nova" leitura, um "Benveniste para o futuro", conforme nos foi proposto. Busquei, entretanto, ter o cuidado de construir uma reflexão que não desconsidere o conjunto, o sistema, a historicidade da obra de Benveniste.

Benveniste começa seu artigo afirmando que se tem a impressão de que, para os linguistas da época (1963),

[...] os fatos da linguagem se trasmudam em abstrações, se tornam nos materiais inumanos de construções algébricas ou servem de argumentos a discussões áridas sobre método, e de que a lingüística se afasta das realidades da linguagem e se isola de outras ciências humanas (p. 19).

\footnotetext{
- Professora do curso de Letras e do Programa de Pós-Graduação em Letras da Universidade Federal de Pelotas (UFPel). E-mail: daiane_neumann@hotmail.com
} 
No entanto, o linguista discorda veementemente dessa afirmação, dizendo que

[...] esses métodos novos da linguística assumem o valor de exemplo e mesmo de modelo para outras disciplinas, que os problemas da linguagem interessam agora a especialidades muito diversas e cada vez mais numerosas e que uma corrente de pesquisas leva as ciências do homem a trabalhar dentro do mesmo espírito que anima os lingüistas (p. 20).

Ora, a afirmação trazida por Benveniste sobre o que se diz da linguística da época trata-se de uma crítica que comumente é feita à linguística estrutural, movimento ao qual, não raro, é atrelado o pensamento benvenistiano, justamente por Benveniste ser considerado o linguista que não faz propriamente uma crítica ao estruturalismo, mas o que Rodolfo Ilari, em "O Estruturalismo linguístico: alguns caminhos", publicado em Introdução à linguística - fundamentos epistemológicos, chamou de "revisão". Segundo Ilari,

[...] embora [Benveniste] tenha trabalhado no sentido de aperfeiçoar e divulgar o programa saussuriano, e possa, nesse sentido, ser considerado um representante importante da escola [estruturalista], era bastante diferenciado, por seus interesses e por seus sólidos conhecimentos em linguística histórica indo-europeia (2011, p. 80).

Em tal afirmação de Ilari, podemos observar uma confusão entre o pensamento saussuriano e o movimento estruturalista ${ }^{1}$. No entanto, há uma consideração importante a se destacar acerca do diferencial do linguista Benveniste, o que também foi observado em
Gérard Dessons, em Émile Benveniste: l'invention du discours, ao constatar que Benveniste é um linguista a parte, e por Meschonnic, em "Seul comme Benvensite", como o próprio título do artigo o atesta, publicado em Dans le bois de la langue.

Retificando a afirmação de Ilari no que concerne à identificação do pensamento saussuriano ao movimento estruturalista e ratificando a observação de que se trata de um linguista com um diferencial, cumpre observar que a leitura apresentada por Benveniste do Cours de linguistique générale é bastante particular, o que pode ser comprovado mesmo no texto em questão.

Em um primeiro momento, o linguista busca, em "Vista d'olhos sob o desenvolvimento da linguística", fazer um panorama dos estudos linguísticos, passando, rapidamente, pelos estudos da filosofia da linguagem, pelos estudos da evolução das formas linguísticas, para chegar ao que chamou de "terceira fase", a qual toma por objeto a realidade intrínseca da língua, e visa a se constituir como ciência - formal, rigorosa, sistemática.

Benveniste segue sua reflexão reportando-se ao pensamento saussuriano, reconhecendo que há um princípio que se tornaria o princípio fundamental da linguística moderna, de que a "língua forma um sistema". A noção de estrutura é considerada pelo linguista "o segundo termo da linguística” (2005, p. 22). Além disso, a noção de estrutura toma o caráter secundário também na medi- 
da em que é compreendida como "tipos particulares de relações que articulam as unidades de um certo nível" (2005, p. 22), isto é, relaciona-se a um certo nível, mas não necessariamente à língua toda.

$\mathrm{Na}$ continuidade de sua discussão, o linguista, em momento algum, faz alusão às famosas dicotomias saussurianas. Pelo contrário, ressalta a constatação de que cada uma das unidades de um sistema define-se assim pelo conjunto das relações que mantém com as outras unidades e pelas oposições em que entra, pois se trata de uma entidade relativa e opositiva, afirma Benveniste, citando Saussure. O linguista sírio sustenta ainda que as entidades linguísticas não se deixam determinar senão no interior do sistema que as organiza e as domina, ou seja, não têm valor a não ser como elementos de uma estrutura. No entanto, em primeiro lugar, é o sistema que é preciso destacar e descrever.

A fim de evidenciar a importância das noções de valor e sistema no pensamento saussuriano, Benveniste pontua ainda que a noção positivista de fato linguístico teria sido substituída pela de relação, assim, não se considera mais um elemento em si, nem mesmo procura-se a sua "causa" num estado mais antigo, mas cada elemento é tratado como parte de um conjunto sincrônico. Essa relação está atrelada aos dois planos de que dependem as unidades da língua, o sintagmático e o paradigmático.

Assim, a forma linguística é: $1^{\circ}$ uma unidade de globalidade que envolve partes; $2^{\circ}$ essas partes apresentam-se num arranjo formal que obedece a certos princípios constantes; $3^{\circ}$ o que dá à forma 0 caráter de uma estrutura é o fato de que as partes constituintes exercem uma função; $4^{\circ}$ finalmente essas partes constitutivas são unidades de um certo nível, de modo que cada unidade de um nível definido se torna subunidade do nível superior (2005, p. 24).

Esse caráter denominado por Benveniste "descontínuo" da língua é o que poria em jogo unidades discretas, que faria com que a língua se caracterizasse menos pelo que exprime do que pelo que distingue em todos os níveis. Tal caráter faz com que a língua seja um sistema em que nada signifique em si e por vocação natural, mas em que tudo signifique em função do conjunto, pois a estrutura conferiria às partes a sua "significação" ou a sua função.

A leitura proposta por Benveniste do CLG sugere, conforme postula Henri Meschonnic, em "Seul comme Benveniste", que o linguista não teria feito uma ultrapassagem em relação a Saussure, mas um deslocamento nocional, na medida em que o conjunto de sua obra está ao lado de Saussure, mas se oporia, certamente, ao estruturalismo.

É decorrente dessa leitura peculiar, de uma só vez, tanto a aproximação entre as palavras "significação" e "função", quanto a reflexão apresentada pelo linguista na segunda parte do texto, em que se segue uma discussão de uma linguística que se constrói com base naquela apresentada na primeira parte. 
Benveniste inicia esse segundo momento do texto, afirmando que "não é apenas a forma linguística que depende dessa análise; convém considerar paralelamente a função da linguagem" (2005, p. 26). A palavra "função", pela reflexão que se segue parece abarcar não somente o sentido já explorado anteriormente ao relacioná-la a "significação", mas também aquele explorado no verbo "servir", ao ser ligado ao "viver", em "a linguagem serve para viver", do texto "A forma e o sentido na linguagem".

Ainda no mesmo texto, após enunciar que "bem antes de servir para comunicar, a linguagem serve para viver", Benveniste segue afirmando que

[...] se nós colocarmos que à falta de linguagem não haveria nem possibilidade de sociedade, nem possibilidade de humanidade, é precisamente porque o próprio da linguagem é, antes de tudo, significar (2006, p. 222).

Conforme Gérard Dessons, em Émile Benveniste: L'invention du discours, esse excerto nos leva a estabelecer uma relação entre "a ação de significar" e "aquela de viver", o que definiria

[...] a natureza irredutivelmente antropológica da linguagem; ou seja, que a linguagem humana possui de próprio a capacidade de definir um pelo outro a vida e o sentido (2006, p. 89).

Vista d'olhos sob o desenvolvimento da linguística articula a reflexão que se segue sustentando essa consideração de que é preciso atentar para a "função" da linguagem. Para explorá-la, o linguista destaca o fato de que a linguagem representa a mais alta forma de uma faculdade que é inerente à condição humana, a faculdade de simbolizar. É a partir dessa capacidade que Benveniste distingue o homem do animal, já que o "homem inventa e compreende símbolos; o animal, não" (2005, p. 29). A própria ascensão de Homo na série animal, segundo o linguista, deve-se antes de tudo à sua faculdade de representação simbólica, fonte comum do pensamento, da linguagem e da sociedade. Assim, fora da esfera biológica, a capacidade simbólica é proposta como a capacidade mais específica do ser humano.

Considerando a linguagem como uma propriedade do humano, Benveniste destaca o fato de que a cultura também o é, já que se trata de um fenômeno inteiramente simbólico. Logo, o homem assimilaria, perpetuaria ou transformaria a cultura pela língua. $O$ linguista então é levado a afirmar que definitivamente é o símbolo que prende esse elo vivo entre o homem, a língua e a cultura.

Dessa forma, não é possível a existência de pensamento sem linguagem, por conseguinte, o conhecimento do mundo é determinado pela expressão que ele recebe, a linguagem, portanto, "reproduz o mundo, mas submetendo-o à sua própria organização" (2005, p. 26). Nesse sentido, o pensamento não pode ser reduzido a um simples reflexo do mundo, pelo contrário, classifica a realidade, o que leva Benveniste a observar que o pensamento, nessa função organizadora, está tão estreitamente associado à 
linguagem, que se pode ser tentado a identificar pensamento e linguagem sob esse aspecto.

Ademais, o linguista, ainda discutindo sobre a "função" da linguagem, destaca que é "dentro da, e pela, língua que indivíduo e sociedade se determinam mutuamente" (2005, p. 27). Considerando a reflexão de que a sociedade não é possível a não ser pela língua; e, pela língua, também o indivíduo, Benveniste destaca o poder fundador da linguagem que "instaura uma realidade imaginária, anima as coisas inertes, faz ver o que ainda não existe, traz de volta o que desapareceu" (2005, p. 27).

A discussão elaborada pelo linguista, ao atentar para o fato de que a língua tem papel fundamental na construção do pensamento, da sociedade, da cultura, leva-nos a reler as afirmações apresentadas no início da segunda parte do texto, "a linguagem reproduz a realidade" realidade é produzida novamente por intermédio da linguagem" e "aquele que fala faz renascer pelo seu discurso o acontecimento e a sua experiência do acontecimento" (2005, p. 26), considerando toda a sua força. Assim, a linguagem sendo constitutiva do homem, da sociedade e das relações intersubjetivas, alcança o seu caráter fundamental, o de ser ao mesmo tempo ética e política. Isso significa que não é possível desvincular o uso da linguagem da constituição de uma subjetividade e ao mesmo tempo de uma tomada de posição, de uma ação de linguagem sobre a realidade.
Ao finalizar o texto "Vista d'olhos sobre o desenvolvimento da linguística", referindo-se especificamente à segunda parte, o linguista afirma que

[...] tudo leva a crer que essas pesquisas paralelas gerarão novas disciplinas e concorrerão para uma verdadeira ciência da cultura que fundará a teoria das atividades simbólicas do homem (2005, p. 32).

Assim, Benveniste não apenas apresenta um panorama bastante rico da ciência linguística de sua época, como aponta como futuro para essa ciência uma abertura cada vez maior em relação às outras ciências humanas.

Percebe-se ao final do texto aquilo que pontua Gérard Dessons, em Émile Benveniste: l'invention du discours, que os trabalhos de Benveniste no domínio da linguística geral mudaram a paisagem das ciências humanas, no entanto, como ele propôs uma antropologia histórica da linguagem, ou seja, uma teoria do conjunto, foi preciso associar o que, em geral, até então não se associava: arte, filosofia, sociologia, etnologia, psicanálise, literatura.

A partir da reflexão apresentada em Vista d'olhos sobre o desenvolvimento da linguística, sentimo-nos sensibilizados e convidados a observar a linguagem sob um ponto de vista que parece distante daquele da grande maioria dos linguistas, mas bastante próximo daquele de grandes poetas.

É impossível adentrar em um texto que pontua de forma tão marcante o que Henri Meschonnic chamaria mais tarde de uma "antropologia histórica da 
linguagem" e não perceber que as palavras de Benveniste ressoam naquelas de Guimarães Rosa que, em entrevista a Günter Lorenz, afirma que

[...] a linguagem e a vida são uma coisa só. Quem não fizer do idioma o espelho de sua personalidade não vive; e como a vida é uma corrente contínua, a linguagem também deve evoluir constantemente. Isto significa que, como escritor, devo me prestar contas de cada palavra e considerar cada palavra o tempo necessário até ela ser novamente vida. O idioma é a única porta para o infinito, mas infelizmente está oculto sob montanhas de cinzas. Daí resulta que tenha de limpá-lo, e como é a expressão da vida, sou eu o responsável por ele, pelo que devo constantemente umsorgen (1994, p. 47).

Manoel de Barros destaca constantemente em sua obra o poder fundador da linguagem, o que se pode perceber no título de uma delas "Memórias Inventadas: a Infância" e já na primeira página dessa obra, quando afirma "Tudo o que não invento é falso". Para Manoel de Barros, o escrever, o enunciar, o trabalhar com a linguagem está ligado a uma atividade de criação, de construção.

Conforme pontuei em meu trabalho de tese, denominado Em busca de uma poética da voz, Charles Baudelaire (1980), em L'Art philosophique, ao discutir sobre "l'art pur", segundo a concepção moderna, a define como a criação de uma magia sugestiva que contém ao mesmo tempo o objeto e o sujeito, o mundo exterior ao artista e o artista mesmo. Tal definição leva a uma mudança de ponto de vista sobre a linguagem no século XIX. Dessa forma, a linguagem enquanto criadora não seria mais metáfora, na me- dida em que não seria possível dissociar o que é dito da maneira como se diz. A individualidade é diluída na medida em que há uma relação entre identidade e alteridade.

A modernidade teria, assim, como lugar, o sujeito, como tempo, o sujeito. Baudelaire transforma a noção de linguagem, ele mostra que só o discurso transforma a língua, que só um sujeito transforma o discurso, que só o ritmo pode mudar as formas de construção de sentido. Assim, as formas históricas do discurso são uma parte da história da individuação, ou ainda, a história da individuação e a história das formas do belo na linguagem são solidárias. De acordo com Meschonnic (1989/2006), há em Baudelaire uma mudança total de óptica, pois claramente se percebe que só pode existir o sujeito no discurso, e não na língua, além disso, o belo na linguagem passa a ser uma aventura de historicidade. Se a linguagem está estreitamente ligada ao processo de individuação, então o que se denomina "belo da linguagem" estaria no ordinário mesmo, naquele de todos os dias; como consequência, a beleza não seria mais formal, nem mesmo semântica, ela seria exatamente a crítica a esse dualismo.

Nas palavras de Meschonnic (2006), em La rime et la vie, a separação entre a linguagem e a vida decorre de uma racionalização da linguagem, que produz o que Humboldt chamou de "esqueletos mortos". Dessa forma, separou-se, de uma só vez, a linguagem da vida e a lin- 
guagem da poesia. Para o poeta, linguista e tradutor, a poesia é a organização na linguagem daquilo que sempre foi considerado algo que escapava da linguagem, a vida, o movimento daquilo que nenhuma palavra cessa de poder dizer.

Meschonnic (1989/2006), em sua reflexão, parece nos apontar um caminho possível, em termos de pesquisa, para que se busque essa aproximação entre linguagem e vida: a aproximação entre língua e literatura. O poema é concebido pelo teórico como a transformação de uma forma de linguagem por uma forma de vida e de uma forma de vida por uma forma de linguagem, na medida em que se configura como a subjetivação máxima, integral de um discurso, que, por isso, pode constituir-se em um sistema de discurso.

A poesia é percebida pelo teórico da linguagem como o único modo de linguagem capaz de dizer o que não pode ser dito, na medida em que ela incorpora o silêncio, ou seja,

[...] quando a realidade ultrapassa todos os meios de nomeá-la, ela só pode ser abordada de uma maneira indireta, através de reflexos que ela projeta na subjetividade de alguém $^{3}$ (MILOSZ, Témoignage de la poésie, p. 124, apud MESCHONNIC 1989/2006, p. 229).

Dessa forma, a escrita se torna uma forma de vida, movimento de uma fala, invenção do sujeito pela sua linguagem e de uma linguagem por seu sujeito inseparavelmente, invenção de sua própria historicidade. Se a escrita é aquilo que advém quando algo é feito na linguagem por um sujeito, e que não havia sido feito até aquele instante por um sujeito, então, pode-se afirmar que a escrita participa de um desconhecido.

Além de a poesia ser um lugar profícuo para o trabalho do estudioso da linguagem que busca pensar a subjetividade na linguagem, intriga e desafia na medida em que como pontua Paulhan (1966-1970, t. II, p. 267, apud MESCHONNIC, 1986/2006, p. 86), “o que nós vimos não é em absoluto que a poesia escapa à condição da linguagem comum. É exatamente o contrário." 4 Ou seja, o mistério que encanta todos os olhares fascinados está na "linguagem mais elementar" (MILOSZ, Témoignage de la poésie, p. 124, apud MESCHONNIC, 1986/2006, p. 229).

No entanto, parece-me que aproximar a linguagem e a vida, em nossas pesquisas, também significa repensar a análise linguística, significa buscar dar conta de uma análise que tente considerar aquilo que "escapa" aos métodos tradicionalmente utilizados e que decorrem de uma racionalização da linguagem. Trata-se de passar de um olhar que busca unidades duais e descontínuas, para buscar um movimento contínuo do discurso.

Essa inquietação não é nova para aqueles que estudam a obra de Émile Benveniste no Brasil, eram muito evidentes as inquietações constantes do professor Valdir Flores, em suas aulas, acerca de como dar conta de uma análise que se queira benvenistiana, sem reduzi-la às marcas da enunciação. 
Gérard Dessons, em Émile Benveniste: l'invention du discours, afirma que reduzir o pensamento benvenistiano às marcas enunciativas é fazer uma leitura caricatural do linguista, já que desconsidera uma grande parte da reflexão sobre linguagem proposta pelo linguista.

Embora não considere que a proposta de Meschonnic, em especial a partir de sua poética do ritmo, dê conta de abarcar isso que nos escapa na análise linguística, parece-me que se trata de uma possibilidade a ser vislumbrada para que se comece a pensar em outras possibilidades de análise. Nessa perspectiva, busca-se considerar aquilo que perpassa as unidades discretas da língua, outras relações de sentido que podem se estabelecer em um discurso, que estejam para além das unidades descontínuas da língua.

Para esse estudioso da linguagem, os textos e as obras formam sistemas de valores que trabalham uma semântica específica, diferente do sentido lexical, o que nos conduz à observação de marcas linguísticas e extralinguísticas que podem estar situadas em todos os níveis da linguagem - acentual, prosódico, lexical, sintático - os quais constituem juntos um paradigma e um sintagma.

Ao analisar o discurso, então, como um sistema, cumpre atentar para a não separação entre som e sentido, para a consideração, em consequência, dos aspectos acentuais e prosódicos da linguagem na análise linguística. $\mathrm{O}$ discurso não é mais visto como aquele que apresenta unidades duais e descontínuas, mas como um contínuo, onde o movimento de significar tem seu corpo, seus gestos, sua voz, sua história.

Seria então somente saindo da língua e entrando no contínuo do discurso-ritmo-e-prosódia-do-sentido, segundo Meschonnic (1989/2006), que os fonemas apareceriam como uma rede de significância. Para a língua, eles seriam vazios de sentido. $\mathrm{O}$ discurso faz deles valores, num sistema de significância. $O$ discurso abriria para uma antropologia do infinito, infinito da linguagem, infinito do sujeito. É nesse sentido que o poeta, linguista e tradutor propõe que o estudo da linguagem configure-se como a busca do desconhecido na linguagem, que nos ensina novas formas de ler, de escrever, de significar.

Trata-se não mais de investigar o que diz um discurso, mas o que ele faz e como o faz, pois o jogo do associativo e do sintagmático é sempre único, singular, inventado por um discurso em particular. Nesse contínuo de subjetivação de um sistema de discurso, o sujeito se inventa pelo e no seu discurso, que, por sua vez, inventa uma historicidade nova. Nessa busca, há a implicação recíproca entre linguagem, ética e história. 


\section{Le langage et la vie: réflexions sur langue et littérature}

\begin{abstract}
Résumé: Cet écrit a pour objectif de présenter une lecture du chapitre intitulé "Coup d'œil sur le développement de la linguistique ", figurant dans le premier volume de l'ouvrage d'Émile Benveniste Problèmes de Linguistique Générale (I). La présente réflexion vise à montrer la singularité de la lecture de la pensée saussurienne par É. Benveniste, et ce que ce dernier a proposé en tant que successeur de cette linguistique déjà existante. Dans la seconde partie de ce travail, s'offre une discussion impliquant langue et littérature, dans la continuité de la pensée benvenistienne et sous la précieuse influence de la poétique du discours de Henri Meschonnic.
\end{abstract}

Mot-clé: le langage et la vie; langue et littérature; É. Benveniste; H. Meschonnic.

\section{Notas}

1 Segundo Meschonnic (2008), a língua e a fala, a diacronia e a sincronia, e o paradigma e o sintagma foram transformados em pares de exclusão pelos estruturalistas. No entanto, Saussure não é um estruturalista, na medida em que para ele, a fala não é excluída do sistema de signos que é a língua, ela é somente distinta como objeto de estudo, mas não no seu funcionamento.

2 No original, lê-se "le langage re-produit la réalité". Deve-se, portanto, atentar para o fato de que a tradução não só "apaga" o destaque dado ao prefixo "re", no texto original, como também não opta pelo uso de itálico. Dessa forma, negligencia o valor crítico de tal morfema na obra do linguista. De acordo com Dessons (2006), glosado pela locução "à nouveau" (novamente), o prefixo "re" passa a portar dois valores, de iteração e de invenção. Proponho que se traduza tal passagem da seguinte maneira: re-produz a realidade.

3 Tradução minha.

4 Tradução minha.

\section{Referências}

BARROS, Manoel de. Memórias inventadas: a Infância. São Paulo: Planeta, 2003.

BAUDELAIRE, Charles. Euvres complètes. Paris: R. Laffont, 1980.

BENVENISTE, Émile. Vista d'olhos sobre o desenvolvimento da lingüística. In:

Problemas de lingüística geral I. Campinas: Pontes Editora, 2005.

A forma e o sentido na linguagem. In: _. Problemas de lingüística geral I. Campinas: Pontes Editora, 2005.

DESSONS, Gérard. Émile Benveniste, l'invention du discours. Paris: Press, 2006.

LORENZ, G. Diálogo com Guimarães Rosa. In: Obras completas de João Guimarães Rosa, Vol. I. Rio de Janeiro: Nova Aguilar, 1994.

ILARI, Rodolfo. O estruturalismo linguístico: alguns caminhos. In: BENTES, Ana Christina; MUSSALIM, Fernanda. Introdução à linguística: fundamentos epistemológicos. São Paulo: Cortez, 2011.

MESCHONNIC, Henri. La rime et la vie. France: Éditions Verdier, 1989/ Gallimard, 2006.

Seul comme Benveniste. In: Dans le bois de la langue. Paris: Editions Laurence Teper, 2008.

NEUMANN, Daiane. Em busca de uma poética da voz. Tese (Doutorado em Letras) - Instituto de Letras, Universidade Federal do Rio Grande do Sul. Porto Alegre, p. 173. 2016. 